\title{
THE ACTUARY: THE ROLE AND LIMITATIONS OF THE PROFESSION SINCE THE MID-19th CENTURY
}

\author{
HANS BÜHLMANN*
}

\section{ETH Zürich}

The history of any profession relates to the history of the division of labour in society. This is generally true and can also be attributed to expertise in the financial world - a world which generates with increasing complexity growing numbers of specialists offering know-how and expertise. The competition amongst these different specialists as to whose services are the more useful, valuable or promising is a phenomenon which is more than simply personal. Individuals with similar training and a common base of knowledge form groups which promote in corpore their competence in certain specialised services. Such a group, which also assumes the responsibility of guaranteeing the qualifications of its members, is usually called a "profession".

The profession of the actuary is one of the oldest in the financial world. There are also accountants, underwriters, statisticians, demographers, operations researchers and financial engineers to name but a few. Allow me now to attempt to place the actuarial profession in this area of professional conflict. There can be no doubt that we actuaries have constantly increased our area of competence since our professional beginnings in the last century. But to maintain that we are the only ones to have done so would be inappropriate.

\section{Phase one: Consolidation of life insurance}

To understand what actuaries are is not possible without knowing where their roots lie. Actuarial organisations owe their existence to a unique service to society which originated in the second half of the last century. I would like to point out that I consider this to be a worldwide achievement and not one limited to a British context, although history books emphasise this aspect. The latter was indeed chronologically first : in Victorian England - the world's leading nation-developments occurred somewhat earlier than in other countries. But the same developments took place in Germany, France, Scandinavia, USA and even in Japan and Australia, for example, a few decades later. What is this co-called unique service? Actuaries of the second half of the last century managed to gain recognition for their mathematical doctrine from the entire life insurance industry worldwide. The essential elements of this doctrine had already been around for almost a century and in fact James Dodson formed the Equitable Life Assurance Society on its principles in 1762 .

\footnotetext{
* Translation of a talk held at a meeting of the "Deutsche Aktuarvereinigung" in Würzburg, April 30, 1997.
}

ASTiN BULLETIN, Vol. 27, No. 2, 1997, pp. 165-171 
For such an astounding achievement, conditions at the time had to be favourable. The first condition being that in the first half of the last century life insurance was to a large extent speculative business. An insurance chronicler wrote: "Insurance companies writing life business were breeding like flies in the summer sky, and disappearing just as fast". The reason for this disappearance was the nonapplication of a proven base for premium calculations on the one hand, and above all the lack of method in the excessive distribution of profits to the entrepreneurs on the other. To give a concrete example: between 1844 and 1853, in Great Britain 335 new insurance companies were planned, 149 were actually formed and a total of 59 survived this period. This called for legislative measures to protect the insured. Secondly, it is just as important to note that Equitable, founded in 1762 as I mentioned earlier, managed to weather all storms in good shape and flourished because of the scientific methods it employed. Other companies thus took over the insurance technique developed mainly by its actuary William Morgan to calculate reserves, create a technical balance sheet and develop mortality tables using statistical data.

This professional know-how had already begun to spread by word of mouth beyond national boundaries. Legislative bodies in most industrial nations were thus able to adopt a tried and tested scientific and mathematical technique. What had once been only a competitive edge for some life insurance companies was suddenly the norm, and the pioneers of this technique became members of the leading industrial profession.

It was this high status of actuaries which led to the formation of the first national actuarial bodies, the Institute of Actuaries in London in 1848, the Faculty of Actuaries in Edinburgh in 1856, and the Institut des Actuaires Français in 1889. This was also the year that the first professional actuarial body was formed in America which was the forerunner to today's American Society of Actuaries. It is also interesting to note early developments in Germany. As early as 1860 , a group of mathematicians met regularly to discuss problems related to the insurance industry. This group published its ideas mainly in the Masius Rundschau der Versicherungen, with extremely innovative contributions by Zillmer and Hattendorf for instance. My efforts to find the exact date on which the Deutsche Gesellschaft für Versicherungsmathematik was formed were unfortunately unsuccessful, though it is known that the Institut für Versicherungswissenschaften with an actuarial department at the University of Göttingen was founded in 1895. Looking to the Far East, I would like to add 1897 and 1899 as the dates when the Australian Institute of Actuaries and the Institute of Actuaries of Japan were formed respectively. As you all know from the recent anniversary celebrations, the first International Congress of Actuaries took place in Brussels in 1895, which additionally led to the formation of the Belgian ARAB.

The circumstances which I have just described provided the basis for the golden age of the actuary spanning the first half of the 20 th century. This period was characterised by the proud awareness that actuaries controlled the know-how and expertise in the area of life insurance, which formed the solid foundation for an entire industry. Managers often came from this profession and used their managerial position to maintain the high status of actuaries within the company. 


\section{Phase 2: Lack of challenge}

This portrayal of the golden age of the actuary is a little one-sided. I first came into contact with the profession in the 1950s as a young actuary and it would perhaps be interesting to hear my personal impressions on joining the world of life insurance. It was probably the same for most of my young colleagues of that time:

I was additionally fortunate in that I had a job with a company which was characterised by outstanding personalities, offered me excellent opportunities for development and, last but not least, paid very well. I soon realised that my mathematical knowledge gained at university was regarded as a welcome status symbol, but that my command of languages and other general knowledge gained at high school were far more important than mathematics. My dear teacher and supervisor at work, Professor Jecklin, summarised this so: actuarial science is a "ready-made" theory; all that remains to be done is the tuning of fine technical details. He could also have said that actuarial science has devoted itself to statics after it had mastered the dynamic conditions of the last century. For a young actuary this meant that a career in the insurance industry may well have offered an attractive entrepreneurial challenge, but the creative side of mathematics would be nothing more than a hobby. Despite the undertone in these statements, $I$ hope that you will not find my impressions too negative; I later came to believe that viewed from the inside, i.e. from the point of view of someone who joined the insurance industry, working in this branch definitely had its attractions; admittedly these were highly dependent on individual situations.

But, as you know all too well, this looked different viewed from the outside. It was difficult to convince students or anyone from academic institutions in general that a profession which uses mathematics statically, but produces no dynamic scientific development of its own, can be attractive. In the first half of the century, the recruiting of young academics interested in actuarial science began to suffer because of this. The situation was made more desperate by the fact that the universities asked themselves-from an academic angle quite justifiably-whether there was still a need to continue with actuarial science chairs; the declining interest shown by students was accompanied by the academic questioning of the lack of innovative ideas in actuarial science. This led to the bizarre situation, for example in Germany, where, on the one hand, the insurance industry wanted to promote actuarial chairs-even offering to support them financially-but on the other, the universities accepted these offers rather reluctantly, if at all. This situation could not only be observed in Germany: it was mirrored the world over. In the Anglo-Saxon countries it merely took another form: universities assumed the role of preparatory schools for examinations without having a say in their content. It is well known that the examination content in the US and Great Britain for example is set by the professional bodies, which meant that until only 20 years ago actuarial exams contained little on mathematics from the 20th century.

In broader terms, not too long ago it could be ascertained that, professionally, the actuary was flourishing while, academically, his reputation was low. 


\section{Phase 3: New impulses}

In the $1960 \mathrm{~s}$ and $1970 \mathrm{~s}$, the actuaries began to break out of the domain of life insurance. The scenario for the acceptance of actuarial methods in non-life insurance was interestingly similar to the one of a hundred years ago in the life branch.

Motor liability in particular was responsible for the enormous losses suffered by insurers in many countries. Even if companies took the trouble to collect statistical data thoroughly they had no clear concept of how premium discounts should be rated. It needed a sound, theoretical approach to bring order to the proliferation of the system.

As in life insurance, the theoretical approaches were once again already in place. In 1903 the Swede Filip Lundberg published the first paper on what was later to become known as collective risk theory. In this publication, he made the pioneering step towards modelling insurance events as a mechanism of chance developing over time. Without knowing, he had used the key concept of modern probability theory - the stochastic process - for the first time in an insurance context. His problem was that in 1903 there was no exact theory of stochastic processes in the strict mathematical sense. The relevant rigorous mathematical foundations were laid in the 1930s and 1940s, mainly by Russian mathematicians. Although Lundberg's work caught the attention of actuaries, it was understood by few, until Professor Harald Cramér's excellent didactic explanations made the relationship between collective risk theory and the theory of stochastic process apparent to a wide readership.

And yet Lundberg's contribution was the most important one. He dragged actuarial science form the intellectual "constraints" of the past into the 20th century. Through his efforts a milestone was reached: modelling the processes of insurance events on the basis of modern probability theory.

The mathematically precise structure of the bonus-malus system in motor liability insurance, based on the number of losses of individual insureds, is a prime example of such a model. This model became established worldwide during the $1960 \mathrm{~s}$. It was also the driving force which offered actuaries new opportunities for professional development outside the field of life insurance. This development soon spread to fire insurance, reinsurance and other branches.

It is interesting to consider whether the activities of actuaries outside the field of life insurance actually contributed to the widening of the limits of the existing profession or whether a second, new profession was thereby created. In the US, where this professional development took place quite earlier than in other countries, it led to a clear separation between Life Actuaries and Casualty Actuaries. In all other countries of the world, however, this widening of competencies has been kept under the same roof. We must nevertheless continually ask ourselves what actually keeps us under the same professional roof. Moreover, in comparison to his colleagues in life insurance, the boundaries of the non-life actuary's competence are a lot more blurred with other professions such as auditors or underwriters. We may regret this, but the pressure of always having to prove oneself in competition with other professions through particularly good performance also has its positive aspects. 


\section{Phase 4: The challenge from other professions}

In defining the limits of actuarial competence we have so far only considered the profession from the inside. We have seen how the actuary clearly marked his professional field as his own, foremost in life insurance, in order to then extend it into other insurance branches.

Another trend has also been evident over the last 40 years, namely the establishing of competencies in other professions whose areas of competence overlap with those of the actuary. Generally speaking, I believe that this development can be attributed to the fact that the concept of probability has, in modern times, become a universal way of thinking which is incorporated in all aspects of our life; in the last century, this concept was relevant to practically only two types of people: to professional gamblers - and actuaries. Another profession which has integrated the concept of probability increasingly since the middle of this century is that of accountants. They, too, often determine the present value of cash flows. Because they do this partly in accordance with principles which differ from actuarial ones, there is inevitably friction between the two professions. This also means competition in activities which were previously reserved exclusively for actuaries. From an economic point of view, there is nothing to be said against the existence of different professional doctrines to treat identical economic problems. On the contrary, the range of possible means available to business managers should be enhanced by this co-existence.

The example of actuary and accountant shows, however, that the overlapping of competencies from different professions can lead to disagreement on which one has an intellectual monopoly on the correct solution to a problem. I believe that it is precisely the role of actuaries to point out how restricting it is to suppose that for a given problem there is only one right answer. This is not even true in mathematics, let alone in economics (as an aside, the closeness of the actuary to mathematics may also be responsible for the fact that, mostly, the claims to a monopoly come from the other side).

The challenge actuaries face from another, newly created profession is however much greater than that which has come from the ranks of the accountants over the last few decades. This latest profession is so new that there is only an English name for it. "Financial Engineers", as they are known, have initially taken up activity in an area which was not previously occupied by any profession. We could therefore speak of unconquered territory or no-man's-land. The typical activities are: pricing of options, term structures for interest rates, optimisation of investment portfolios; in short, the problems of the modern financial world.

Looking back it is difficult to understand why the approaches and solutions developed for today's financial sector, which are clearly oriented towards mathematics, or to be more precise towards probability theory, did not originate from the breeding-ground of actuarial thinking. This is also true of the academic world; here, the innovation stemmed from the faculties of business administration, i.e. the business schools. The challenge from financial engineers is thus of a different type. It has shown us that a static profession can miss obvious chances of key importance to its professional development. The traditional thought patterns of financial 
mathematics kept us chained for too long to deterministic, non-variable, technical interest rates for the entire duration of an insurance contract. But the actuaries have woken up and are beginning to occupy the field of modern financial mathematics around the world.

The universities in particular have realised that finance and insurance mathematics should be presented to today's students as one discipline. I personally favour a fruitful co-existence of the paradigms which have grown from different breedinggrounds and which may lead to different practical solutions. In the resulting competition between the two professions, the actuaries have the disadvantage of having been somewhat late arrivals in the field. In many places, however, the training of actuaries concentrates more on mathematics than courses at business schools do. This long-term advantage should not be underestimated. And why can't the actuarial roof be big enough to cover financial engineers too?

\section{The "common" roof for actuaries}

What exactly is this "common" roof? How wide should it be and how diversified can the profession be which it covers? What does it mean: "we are all actuaries"? Is it not more helpful to say that you carry responsibility for the calculation of reserves in life insurance, for the rating of substandard risks in life and health, for loss statistics in fire insurance, for the development of derivatives at a reinsurance company or for demographical projections in social insurance? If we take our daily responsibility as a means of classification, we are-as are members of many other professions - an association of specialists. What does the common profession of actuary mean to us then? The first response to this question comes from the corporative world : the profession of actuaries defines the necessary code of conduct for its members; it ensures professionalism to others and controls conduct from within. Most national actuarial associations are now in the process of revising their rules of conduct. This will help clarify the professional standing of the actuary in today's business and insurance world and is thus a welcome move. Corporate understanding of the profession is, however, not sufficient to define "a common roof". Experience shows that the majority of guidelines developed by the profession is aimed at disjunct groups of specialists and thus contributes little to the unity of members of the profession. This unity requires a communicative understanding of what constitutes a profession; in addition to the know-how of these specialists, it requires in particular an integrated and mutual understanding of what these specialists do and on which basis their know-how is founded. Only in this way can we stop the "common" roof from turning into a tower of Babel. Those of us who work in universities can perhaps make the biggest contribution to our profession in this respect by teaching actuarial mathematics, financial mathematics, non-life and life insurance techniques, capitalisation and "pay-as-you-go" from a common base of understanding. I should perhaps add that the concept of a common basis for the understanding of the modern financial world (of which insurance is a part) is greeted with great enthusiasm by the students. The number of students who actively participate in our seminars on this subject has shot up. What is particularly pleasing 
is that it is often the best students who want to work in the area of integrated finance and insurance mathematics. The future role of the actuarial profession will depend essentially on how successful it is at supporting and encouraging these promising young people after they have graduated. If we can succeed in integrating them actively and professionally in the financial sector, this important sector of our economy will be able to look to the future with confidence.

HANS BÜHLMANN

Department of Mathematics

ETHZ

CH-8092 Zürich

Switzerland 